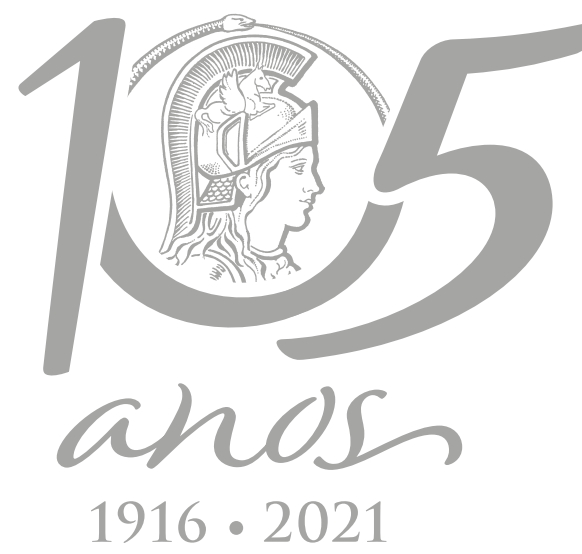

\title{
ECOSYSTEMS
}

\section{Presence of Ascogregarina culicis and Ascogregarina sp. in natural sympatric populations of Aedes aegypti and Ae. albopictus (Diptera: Culicidae) in Argentina}

\author{
ANA C. ALONSO, MARINA STEIN \& MARÍA V. MICIELI
}

\begin{abstract}
Aedes aegypti is the main vector of the four arboviruses in America which have the greatest impact on human health. The introduction of Aedes albopictus in South America and Argentina acquires importance given the possibility that this species may be a new vector of arboviruses in this region. For this reason, the studies of the biology of their parasites, such as Ascogregarina spp., should be important for the knowledge of the invasive behavior of these vectors. We reported the finding of Ascogregarina culicis in Aedes aegypti and Ascogregarina sp. in Ae. albopictus populations in subtropical Argentina. The prevalence of parasitism by A. culicis in Ae. aegypti and Ascogregrarina sp. in Ae. albopictus was 34.81\% $(n=464)$ and $37.23 \%(n=70)$, respectively, differing between the seasons and habitats. The infection intensity caused by A. culicis and Ascogregarina sp. varied between 1 to 250 and 1 to 327 trophozoites respectively. Ascogregarina culicis was found throughout the all sampling period of Ae. aegypti (June 2016-April 2018). However the presence of Ascogregarina sp. in the midgut of Ae. albopictus was not recorded throughout the whole sampling period despite the presence of the host.
\end{abstract}

Key words: Ascogregarina, Culicidae, northeastern Argentina, South America, protozoa.

\section{INTRODUCTION}

Members of the genus Ascogregarina (Apicomplexa: Lecudinidae) are intracellular parasite protozoa of which nine species are parasites of mosquitoes (Culicidae). They are considered mostly non-pathogenic for their natural hosts but are harmful to others (Lantova \& Volf 2014). Ascogregarina culicis (Ross) parasite the mosquito species Aedes aegypti Linnaeus, whereas Aedes albopictus (Skuse) is parasitized by Ascogregarina taiwanensis (Lien and Levine) (Lien \& Levine 1980, Fukuda et al. 1997).

The mosquito larvae become infected when ingesting oocysts present in the water where they develop. Each oocyst consists of eight sporozoites that are released into the gut when they are ingested by the hosts, invading epithelial cells. Within the cells, the sporozoites become trophozoites and are released into the gut lumen when the epithelial cell is broken. There, they become attached to the gut epithelial cells and then, during the pupa stage, they migrate to the Malpighian tubules where they reproduce sexually forming oocysts in the adult mosquitoes. These oocysts are eventually released into the water during female oviposition or at the death of the infected adult mosquito in the habitat (Lantova \& Volf 2014).

The competition through differential infection by Ascogregrarina is one of the hypotheses that would explain the phenomenon of displacement or competition between $A e$. aegypti and Ae. albopictus. This hypothesis 
is based on the differential pathogenicity or asymmetric effects caused by $A$. taiwanensis (a natural parasite of Ae. albopictus), that by infecting Ae. aegypti, it would cause a decrease its density. On the contrary, A. culicis would not infect Ae. albopictus (Munstermann \& Wesson 1990, Blackmore et al. 1995, Juliano 1998, ReyesVillanueva et al. 2001).

Both gregarines are similar morphologically, although they can be differentiated through trophozoites shape. This classification is based on host specificity and morphological characteristics (Reyes-Villanueva et al. 2001, Pereira et al. 2018). In addition, development of molecular tools also allow their identification (Morales et al. 2005).

Nowadays Ae. aegypti is the main vector of the four arboviruses in America which have the greatest impact on human health in the region: the yellow fever virus (YFV), dengue virus (DENV), chikungunya virus (CHYKV) and Zika virus (ZIKV) (Souza-Neto et al. 2019). The introduction of Ae. albopictus in Argentina (Rossi et al. 1999), a species native to Southeast Asia, leave open the possibility that this species might participate as a new vector in the transmission of arbovirosis in the northeastern region of the country. Different experiments have demonstrated that Ae. albopictus populations from Brazil and others American countries are highly competent at transmitting Dengue (DENV), Yellow fever (YFV) and Chikungunya (CHIKV) (Mitchell et al. 1987, Miller et al. 1989, Vega-Rúa et al. 2014).

As regard the Ascogregarina species, studies on this genus of protozoa in South America are scarce and most of them correspond to Brazil (Passos \& Tadei 2008, Prophiro et al. 2017) and the temperate zone in Argentina (Vezzani \& Wisnivesky 2006, Albicócco \& Vezzani 2009). Likewise, researches in Argentina has focused on localities where Ae. aegypti is present, without the presence of Ae. albopictus.
The aim of the present study was to detect the presence of Ascogregarina in sympatric populations of Ae. aegypti and Ae. albopictus collected in different types of habitats, and in different seasons of the year, in Eldorado city, Misiones, Argentina, as well as, to obtain data on the prevalence and intensity of infection of these parasites.

\section{MATERIALS AND METHODS}

\section{Study area}

Eldorado city $\left(26^{\circ} 24^{\prime} \mathrm{S}\right.$; $54^{\circ} 38^{\prime} \mathrm{W}$, at $212 \mathrm{~m}$ ) (Misiones province, northeastern Argentina) (Figure 1) is located in the Paranaense phytogeographic province, belonging to the Interior Atlantic Forest. It is characterized by three arboreal strata with lianas, epiphytes and hemiepiphytes, and an understory of ferns, herbaceous and bushy phanerophytes, including Bambuseae (Oyarzabal et al. 2018). The weather is warm and wet, subtropical without a marked dry season, with large thermal amplitude and abundant precipitations, which denotes its "continental" character and makes this region one of the wettest in the country. The average annual temperature is $22^{\circ} \mathrm{C}$, with a maximum temperature of $38.5^{\circ} \mathrm{C}$ and a minimum of $-5.4^{\circ} \mathrm{C}$; up to 50 days with frost are recorded during the year. The average annual rainfall is $2017 \mathrm{~mm}$; autumn (March to May) is the rainy season (563 mm) (Eibl et al. 1999, Manso Hernández et al. 2010).

\section{Sample collection}

From June 2016 to April 2018 larvae of species of Aedes were monthly collected, covering two warm periods (spring-summer-autumn) and two cold winter periods. Mosquito larvae were sampled in urban area, from artificial containers. The surveys were made in family homes, public places such as cemeteries, and 


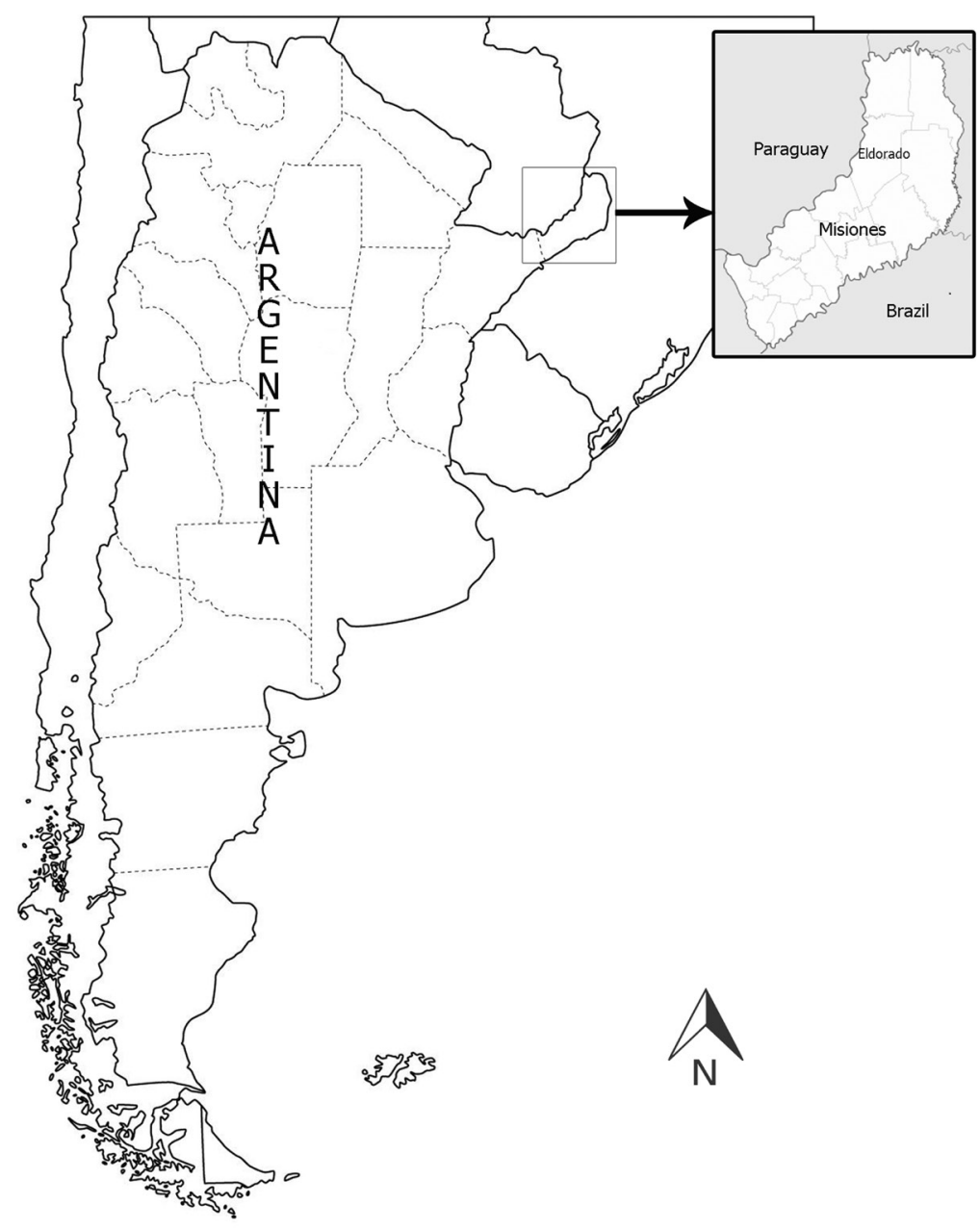

\author{
Figure 1. Location map \\ in Argentina of the \\ province of Misiones, \\ collecting site: city of \\ Eldorado.
}

every urban location with potential habitats for these species (tyre repair workshops, mechanic workshops and scrapyards). The following variables were recorded for each larval habitat: $\mathrm{pH}$, temperature, location of the container with regard to sunlight (sunlight, deep or partial shade) and type of container. At laboratory, the samples were placed in plastic trays and the fourth instar mosquito larvae were taxonomic identified based on characteristics outlined in Consoli \& Oliveira (1994) for inmature Culicidae. Larvae from the first to third instars were reared to the fourth instar for identification.

\section{Dissection of the larval digestive tract}

The containers positive for Aedes spp. were classified into the following categories: positive for Ae. aegypti, positive for Ae. albopictus, and positive for both species. Three containers from each category were chosen at random and ten larvae of instars IV, were taken to perform dissections.

The dissections were performed under a stereoscopic microscope (Zeiss Stemi 2000-C; $1 \mathrm{X})$ with a drop of physiological solution ( $\mathrm{NaCl}$ $10 \%)$, using finely pointed entomology tweezers, holding the larva from the cephalic portion and stretching it from the postabdominal respiratory siphon. Once the digestive tract was extracted, a coverslip was placed over it, to observe under 
a conventional light microscope (Olympus CX31) with 10X and 40X magnifications in search of trophozoites of Ascogregarina spp.

The trophozoites of Ascogregarina spp. were identified following the description provided by Reyes-Villanueva et al. (2001). Photographs were taken with an INFINITY 1 camera, and the length and width of the gregarines were measured.

\section{DNA extraction and amplification}

DNA was extracted from parasitized gut of Ae. aegypti and Ae. albopictus using the Wizard Genomic Purification Kit (Promega). The integrity of the extracted DNA was checked on $1 \%$ agarose gel. PCR was performed as described by Morales et al. (2005), with the primers AU (5'-ACCGCCCGTCCGTTCAATCG-3'), AC (5' CACTTAGTGTTTTGTTTGATGTC 3'), and AT (5' GAGAAGCCGTCGTCAATACAGC 3').

The PCR mixture was performed in a total volume of $25 \mu \mathrm{l}$ containing $3 \mu \mathrm{l}$ of genomic DNA of either Ae. aegypti or Ae. albopictus, $2.5 \mu \mathrm{l}(10$ $\mathrm{pmol} / \mu \mathrm{l})$ of primers AC or AT, $2.5 \mu \mathrm{l}(10 \mathrm{pmol} / \mu \mathrm{l})$ of primers $\mathrm{AU}, 2.5 \mu \mathrm{l}$ of TAS $10 \mathrm{X}$ reaction buffers, $2.5 \mu \mathrm{l}$ of dNTPs (10mM of each deoxynucleoside triphosphate), $0.2 \mu$ l of Taq polymerase (HIGHWAY $5 \mathrm{U} / \mu \mathrm{l}), 3 \mu \mathrm{l}$ of $\mathrm{MgCl} 2(3 \mathrm{mM} / \mu \mathrm{l})$, and $10.8 \mu \mathrm{l}$ of water free of DNAses (Promega). The PCR conditions included an initial denaturation at $94^{\circ} \mathrm{C}$ for $1 \mathrm{~min}$, followed by 30 cycles of $1 \mathrm{~min}$ at $94^{\circ} \mathrm{C}, 1 \mathrm{~min}$ at $50^{\circ} \mathrm{C}$ and $2 \mathrm{~min}$ at $72^{\circ} \mathrm{C}$, with a final extension of $10 \mathrm{~min}$ at $72^{\circ} \mathrm{C}$ (Prophiro et al. 2017). The amplified DNA fragments were visualized by electrophoresis using agarose gels at $2 \%$ supplemented with Gel Red (GenBiotech) under UV light. DNA was purified using the Agarose Gel DNA Extraction Kit (Roche). The genomic fragments were sent to Macrogen Inc. (Seoul, South Korea) for sequencing.

\section{Data analysis}

The spatial-temporal variation of Ascogregarina spp. was evaluated using quantitative descriptors of the parasites' populations according to Bush \& Shostak's definitions of prevalence, the intensity of infection and mean intensity (MI) (Bush et al. 1997). The analysis was performed using the InfoStat / E version 2018 statistical software (Di Rienzo et al. 2018). To compare the seasonal prevalence of infection, the Pearson's Chi-square test was performed. Seasonal MI was compared using the Kruskall-Wallis test and a subsequent pairwise comparison test. In addition, we performed a Spearman's correlation test between the MI and the temperature of the water registered in the microhabitat.

The DNA sequences were visualized and edited with the Chromas free software version 2.6.5. (http://www.technelysium.com.au). Bioinformatic analysis was performed with the BLASTn tool available in the NCBI platform (National Center for Biotechnology Information, https://www.ncbi.nlm.nih.gov/).

\section{RESULTS}

\section{Molecular detection and morphological description of trophozoites of Ascogregarina spp. in larvae of Aedes aegypti and Ae. albopictus}

The trophozoites of $A$. culicis inside and outside the midgut of fourth-instar larva of Ae. aegypti were observed. These infected larvae had normal external color, behavior and appearance. The size of the trophozoites was variable, with an average of $82.22 \mu \mathrm{m}( \pm 21.69)$ in length and $28.27 \mu \mathrm{m}( \pm 9.61)$ in width, $n=49$. The shape looks like comma; the anterior part, consisting of protomerite and epimerite, is wider than the conical part corresponding to the deutomerite (Figure 2a). In Ae. albopictus, trophozoites 

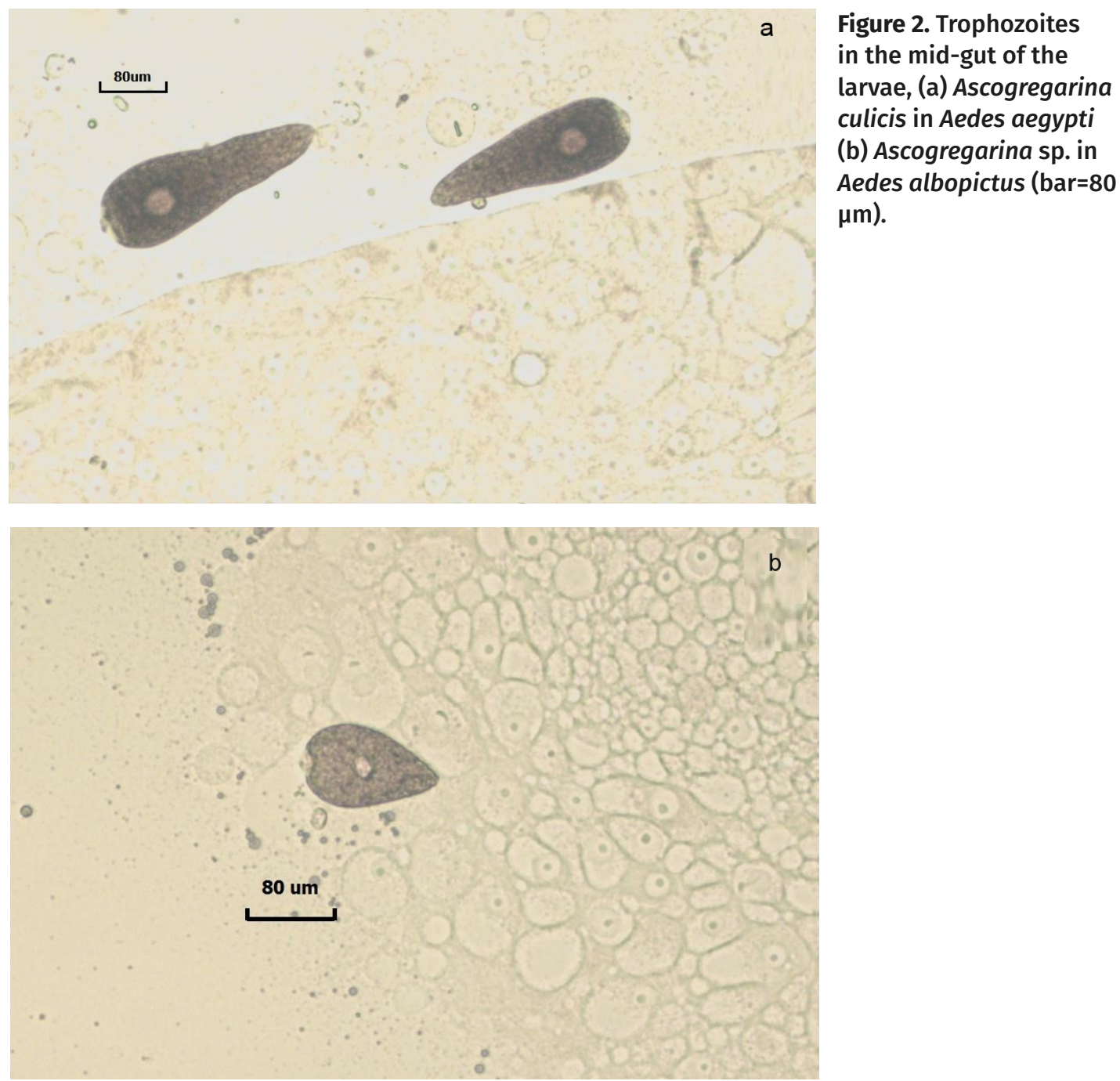

of Ascogregarina sp. had a much shorter deutomerite, ending more abruptly than in $A$. culicis, with a length of $81.60 \mu \mathrm{m}( \pm 20.4)$ and a width of $40.04 \mu \mathrm{m}( \pm 13.24), \mathrm{n}=75$ (Figure $2 \mathrm{~b}$ ).

The sequence obtained from Ae. aegypti corresponding to $200 \mathrm{pb}$ (access number GenBank MK684162) was aligned and revealing an identity of $100 \%$ with other sequences of A. culicis. The sequence obtained from midgut of Ae. albopictus (180 pb) was not sufficient to confirm its identity that is why we named as Ascogregarina sp. Anyway, based on the morphology of the trophozoites and the host specificity, this could potentially be $A$. taiwanensis.

\section{Prevalence and intensity of infection of $A$. culicis and Ascogregarina sp. in different habitats and seasons}

During the sampling period, 1333 larvae of Ae. aegypti and 188 larvae of Ae. albopictus collected from different sites in the city of Eldorado were dissected. The total prevalence of infection was $34.81 \%(n=464)$ and $37.23 \%(n=70)$, for A. culicis and Ascogregarina sp., respectively.

Ascogregarina culicis was found throughout the sampling period, and seasonal prevalence 
showed statistically significant differences (Pearson's Chi-square $=84.59 ; p<0.0001$ ). The highest prevalence of $A$. culicis was observed in spring 2017, both in microhabitats located to sunlight (41.79\%) and deep or partial shade (42.68); and in autumn 2018, in habitats located to sunlight (55.00\%) and deep or partial shade (52.77\%). The greatest abundance of immature of Ae. aegypti was in summer 2017/2018. The intensity of infection of $A$. culicis in larvae of Ae. aegypti varied from 1 to 250 trophozoites. Although significant difference between the seasons was not detected $(H=16.87 ; p=0.0315)$, the highest MI was found in spring 2016 and autumn 2017 (Table I).

The presence of Ascogregarina sp. in the midgut of Ae. albopictus was not recorded throughout the whole sampling period despite the presence of the host. The differences between seasonal prevalence were significant (Pearson's Chi-square $=29.36 ; p=0.0003)$, with the highest prevalence in spring 2016 (60.00\%) and summer 2018 (90.00\%), in both cases the habitats were located at partial or deep shade; the greatest abundances of Ae. albopictus were collected in summer 2018. The intensity of infection varied from 1 to 327 trophozoites per larva. The highest MI was observed in autumn 2018, although the differences were not statistically significant between the seasons $(H=6 ; p>0.9999)$ (Table II).

The highest number of trophozoites for both parasites was observed in autumn and spring, when the mean air temperatures varied between $18.66^{\circ} \mathrm{C}$ and $25.62^{\circ} \mathrm{C}$, respectively.

When comparing the prevalence of infection among different habitats, statistically significant differences were found for $A$. culicis and Ascogregarina sp. (Pearson's Chi-square $=$ 144.97 and 33.13; $p<0.0001$ respectively). The tire was the container with the highest prevalence for both protozoa. On the other hand, the comparison between the average intensity in the different habitats did not showed any significant differences for the two parasites $(H=7.83 ; p=$ 0.4503 and $H=6.76 ; p=0.1493$, respectively).

\section{Micro-environmental habitat conditions}

In the habitats with the presence of $A$. culicis and Ascogregarina sp., the average water temperature was $22.86^{\circ} \mathrm{C}$ (SD 6.02) and $22.85^{\circ}$

Table I. Seasonal infection rates and number of trophozoites of Ascogregarina culicis in natural populations of Aedes aegypti.

\begin{tabular}{|c|c|c|c|c|c|}
\hline & \multicolumn{3}{|c|}{ Sun } & \multicolumn{2}{c|}{ Shade } \\
\hline Season & $\mathbf{N}^{\circ}$ Ae. aegypti & $\mathbf{N}^{\circ}$ trophozoites(MI) & \% infected & $\mathbf{N}^{\mathbf{0}}$ trophozoites & \% infected \\
\hline Autumn 16 & 1178 & $4.9(0)$ & 24.39 & - & - \\
\hline Winter 16 & 629 & $12.56(11.89)$ & 18.32 & $55.50(0)$ & 42.10 \\
\hline Spring 16 & 2127 & $30.22(16.1)$ & 23.53 & $18.57(14.84)$ & 41.17 \\
\hline Summer 16/17 & 3171 & $23.16(14.37)$ & 37.12 & $22.5(12.35)$ & 16.76 \\
\hline Autumn 17 & 2361 & $51.67(23.1)$ & 28.71 & $26.03(36.3)$ & 26.44 \\
\hline Winter 17 & 1035 & $8.06(9.98)$ & 31.25 & $13.75(0)$ & 18.18 \\
\hline Spring 17 & 4007 & $37.27(25.35)$ & 41.79 & $15.7(14.28)$ & 42.68 \\
\hline Summer 17/18 & 4411 & $13.42(16.83)$ & 1.66 & $11.44(10.31)$ & 25.27 \\
\hline Autumn 18 & 1138 & $30.88(6.9)$ & 55.00 & $60.13(48.83)$ & 52.77 \\
\hline
\end{tabular}

${ }^{1}$ Mean \pm SD. 
C (SD 4.07), respectively. The water temperature and the average number of trophozoites of $A$. culicis presented a negative correlation, but not significant ( $r s=-0.11 ; p=0.3608$ ). In the case of Ascogregarina sp. the correlation was not significant ( $r s=0.1 ; p=0.7518$ ).

\section{DISCUSSION}

Our observations provide information regarding the parasites of Ae. albopictus and Ae. aegypti in sympatric populations from Argentina. We reported the finding of Ascogregarina culicis in Aedes aegypti and Ascogregarina sp. in Ae. albopictus populations in subtropical Argentina for the first time.

Researches related to the morphology of trophozoites has revealed size differences between geographical isolations and depend largely of the host in both species (Garcia et al. 1994, Reyes-Villanueva et al. 2001). Our study found that the size of trophozoites of $A$. culicis is smaller than that reported by ReyesVillanueva et al. (2001) for a strain from Florida (USA). Dellapé et al. (2005) reported Ae. aegypti infected with $A$. culicis for the first time in
Buenos Aires, Argentina; they founded smaller trophozoites than those reported in the present study (59.3 $\mu \mathrm{m}$ long and $12.1 \mu \mathrm{m}$ wide). Then, Albicócco \& Vezzani (2009) recorded the size of A. culicis as being 76.88-116.56 $\mu \mathrm{m}$ long and 11.6$12.4 \mu \mathrm{m}$ wide. Lien \& Levine (1980) described A. culicis for the first time in isolations from Taiwan, corresponding to $170 \mu \mathrm{m}$ long and $26 \mu \mathrm{m}$ wide in the front area. The morphology of trophozoites of Ascogregarina sp. found in Ae. albopictus is similar to that described for A. taiwanensis by Passos \& Tadei (2008) for isolation from Brazil. However, is smaller than that described by Lien \& Levin (1980) (234 $\mu \mathrm{m}$ long and $32 \mu \mathrm{m}$ wide) for an isolation from Taiwan. This demonstrates the difficulty of relying on the size and morphology of trophozoites for identification of gregarine species, thus it is necessary to corroborate with molecular approach. In this study A. culicis was molecularly identified but it not was possible for the gregarine infecting Ae. albopictus. It could potentially be $A$. taiwanensis but accurate molecular identification is necessary to confirm our assumptions based on morphology and host specificity.

Table II. Seasonal infection rates and number of trophozoites of Ascogregarina sp. in natural populations of Aedes albopictus.

\begin{tabular}{|c|c|c|c|c|c|}
\hline & \multicolumn{3}{|c|}{ Sun } & \multicolumn{2}{c|}{ Shade } \\
\hline Season & $\mathbf{N}^{\mathbf{0}}$ Ae. albopictus & $\mathbf{N}^{\mathbf{0}}$ trophozoites & \% infected & $\mathbf{N}^{\mathbf{0}}$ trophozoites $^{\mathbf{1}}$ & \% infected \\
\hline Autumn 16 & 76 & $1.0(0)$ & 25.00 & - & 0.00 \\
\hline Winter 16 & 472 & - & 0.00 & - & 0.00 \\
\hline Spring 16 & 215 & - & 0.00 & $50.0(0)$ & 60.00 \\
\hline Summer 16/17 & 407 & $8.00(0)$ & 50.00 & $42.64(48.94)$ & 40.74 \\
\hline Autumn 17 & 661 & $12.18(5.44)$ & 36.66 & $50.93(64.04)$ & 39.39 \\
\hline Winter 17 & 128 & - & 0.00 & - & 0.00 \\
\hline Spring 17 & 300 & $5.20(7.26)$ & 62.50 & - & 0.00 \\
\hline Summer 17/18 & 1101 & - & 0.00 & $8.78(6.36)$ & 90.00 \\
\hline Autumn 18 & 190 & $123.00(91.27)$ & 52.63 & $26.00(47.48)$ & 42.10 \\
\hline
\end{tabular}

${ }^{1}$ Mean \pm SD. 
The percentage of infection of $A$. culicis infecting larvae of Ae. aegypti found in the present study (34.81\%) was lower than that recorded in Brazil (78\%-95\%) and in the USA ( 50\%-70\%) (Passos \& Tadei 2008, Blackmore et al. 1995). However, this value was higher in relation to previous reports for larvae collected in a cemetery (19.9\%) and females (21.2\%) from populations of Ae. aegypti in a temperate region in Argentina (Vezzani \& Wisnivesky 2006, Albicócco \& Vezzani 2009). The infection of Ae. albopictus by Ascogregarina sp. found in the present study was lower (37.23\%) than those reported for Manaus (Brazil) and Florida (USA), 21\%-39.5\% and 68\%-100\%, respectively for Ascogregarina taiwanensis (Passos \& Tadei 2008, Prophiro et al. 2017).

Ascogregarina culicis was detected throughout the whole sampling period. It is relevant to highlight the presence of $A e$. aegypti during the whole year in the study area (Stein 2018), which would enable a more established infection and a higher prevalence of the parasite. The periods of higher prevalence of Ascogregarina culicis corresponded to higher mosquito abundance in the study area. The meteorological variables influence the abundance of the mosquito vector, which would influence the abundance of the parasite ( A.C. Alonso, unpublished data). This correspondence between the both abundances, host and parasites, is also reported in the temperate region in Argentina, with seasonal patterns proper of those latitudes (Albicócco \& Vezzani 2009).

The intensity and prevalence of infection of A. culicis and A. taiwanensis vary considerably between different regions around the world and even within the same geographical region, as was shown by Passos \& Tadei (2008) in the Amazon region in Brazil. In Eldorado city, Argentina, the intensity of infection of $A$. culicis varied between 1 to 250 trophozoites per larva, lower than that recorded in Manaus, Brazil, which varied between 1 to 582 trophozoites per larva. For Ascogregarina sp. the intensity of infection varied between 1 to 327 trophozoites per larva, similar to that registered by Passos \& Tadei for A. taiwanensis (2008).

In the present study, the total MI of A. culicis was significantly higher than that reported by Albicócco \& Vezzani (2009) (28.94, SD 35.78). This could be related to the continuous presence of the host throughout the year in the subtropical region, whereas in the temperate region, the host is only present as the egg stage in winter and the parasite must to persist in the containers as oocysts.

Our MI values agree with others reported for warm zones. Blackmore et al. (1995) found values varying between 1 and 486 trophozoites in Florida (USA), with MI values of 52.5 parasites per larva for Ae. aegypti and 33.5 parasites per larva for Ae. albopictus.

In addition, the habitats with a greater intensity of infection of both gregarines were those located at shade, protected from sunlight and lower water temperatures, mainly founded in houses and tire workshop.

The tires were the habitats with the higher intensity of infection, probably because these habitats are more protected from sunlight, so it would not reach high temperatures to affect the viability of the oocysts; in addition, the total evaporation of water is not a common event in the tires, so oocysts are not exposed to desiccation.

In coincidence with our findings, Albicócco \& Vezzani (2009) also found the highest prevalence of infection in containers protected from sunlight. Oocysts exposed to high temperatures show a decrease in their viability (McCray et al. 1970). However, in the present study variation in the intensity of parasitism did not correlate 
significantly with the water temperature in the containers.

Parasitism by this protozoan are opened new questions about the possible role of modeler of interspecific competition between Ae. albopictus and Ae. aegypti. Our observations constituting a possible explanation about the restricted distribution of the Aedes albopictus, 20 years after its first finding in Argentina (Lizuain et al. 2019). However, further studies from the effects of gregarines on the coexistence of both Aedes species in this region are needed.

Different studies conducted in other regions of the world, have shown that the infection of A. taiwanensis in Ae. albopictus can lengthen larval development, diminish the adult size and affect female fertility (Aliabadi \& Juliano 2002). We believe that more studies should be done to see if there is a relationship between the low abundance of Aedes albopictus with respect to Aedes aegypti (1/10 - 4/10) registered in the study area (Stein 2018) and the intensity of infection by this protozoan. Despite the continuous presence of the host, the parasite was no monthly detected in the present study and considering that twenty years have passed since the first detection of Ae. albopictus in Argentina, makes us postulate whether or not this species has managed to overcome the parasite escape phase proposed by Aliabadi \& Juliano (2002). In this escape phase, the species would not be highly parasitized by the protozoan in a new distribution area, which could represent a certain inter- and intra-population reproductive advantage that would increase its abundance. However, the lower abundance of Ae. albopictus in relation to Ae. aegypti recorded in Eldorado city, and its restricted distribution in Argentina, would indicate that, up to the present, this mechanism of reproductive advantage has not been enough to enable Ae. albopictus to become an invasive species, as it has been considered in other regions of America.

\section{Acknowledgments}

We thank Mr. Carlos Paredes and the technicians from the Environmental Sanitation Direction of the Municipality of Eldorado for their technical support in collecting specimens. This study was supported by the Fondo Nacional de Ciencia y Tecnología (FONCYT) [PICT 2338/14], an IDB loan, and the Consejo Nacional de Investigaciones Científicas y Técnicas (CONICET) [PIP 2015-0288].

\section{REFERENCES}

ALBICÓCCO AP \& VEZZANI D. 2009. Further study on Ascogregarina culicis in temperate Argentina: Prevalence and Intensity in Aedes aegypti larvae and pupae. J Invertebr Pathol 101(3): 210-214.

ALIABADI BW \& JULIANO SA. 2002. Escape from gregarine parasites affects the competitive interactions of an invasive mosquito. Biol Invasions 4(3): 283-297.

BLACKMORE MS, SCOLES GA \& CRAIG GB. 1995. Parasitism of Aedes aegypti and Ae. Albopictus (Diptera: Culicidae) by Ascogregarina spp. (Apicomplexa; Lecudinidae) in Florida. J Med Entomol 32(6): 847-852.

BUSH AO, LAFFERTY KD, LOTZ JM \& SHOSTAK AW. 1997. Parasitology Meets Ecology on Its Own Terms: Margolis Et Al. Revisited Parasitol 83(4): 575.

CONSOLI RAGB \& OLIVEIRA R. 1994. Principais mosquitos de importância sanitária no Brasil. Rio de Janeiro: Fiocruz, 228 p.

DELLAPÉ ME, MARTI GA, TRANCHIDA MC \& GARCÍA JJ. 2005. First Record of Aedes aegypti (L.) (DIPTERA: CULICIDAE) Infected by the Parasite Ascogregarina culicis (ROSS) (Apicomplexa: LECUDINIDAE) in Argentina. Entomol Vect 12(1): 111-115.

DI RIENZO JA, CASANOVES F, BALZARINI MG, GONZALEZ L, TABLADA M \& ROBLEDO CW. 2018. InfoStat versión. Argentina: Grupo InfoStat, FCA, Universidad Nacional de Córdoba, Argentina [2 March 2019].

EIBL B, MONTAGNINI F, FERNANDEZ R, KOZARIK JC, NOZZI D \& LUPPI A. 1999. Sistemas agroforestales con llex paraguariensis (yerba mate) y árboles maderables nativos en pequeñas propiedades en Misiones Argentina. In: Primeras Jornadas de Trabajo Sobre Ecología de Especies Nativas 
de la Selva Subtropical Misionera: Montagnini, F. Universidad Nacional de Misiones, p. 27-32.

FUKUDA T, WILLIS OR \& BARNARD DR. 1997. Parasites of the Asian tiger mosquito and other container- inhabiting mosquitoes (Diptera: Culicidae) in Northcentral Florida. J Med Entomol 34(2): 226-233.

GARCIA JJ, FUKUDA T \& BECNEL JJ. 1994. Seasonality, Prevalence and Pathogenicity of the Gregarine Ascogregarina taiwanensis (Apicomplexa: LECUDINIDAE) in Mosquitoes from Florida. J Am Mosq Control Assoc 10(3): 413-418.

JULIANO S. 1998. Species Introduction and Replacement among Mosquitoes : Interspecific Resource Competition or Apparent Competition? Ecology 79(1): 255-268.

LANTOVA L \& VOLF P. 2014. Mosquito and Sand Fly Gregarines of the Genus Ascogregarina and Psychodiella (Apicomplexa: Eugregarinorida, Aseptatorina) - Overview of their taxonomy, life cycle, host specificity and pathogenicity. Infect Genet Evol 28: 616-627.

LIEN S \& LEVINE N. 1980. Three new species of Ascocystis (Apicomplexa, Lecudinidae) from Mosquitoes. J Protozool 27(2): 147-151.

LIZUAIN AA, LEPORACE M, SANTINI M, UTGÉS M \& SCHWEIGMANN N. 2016. Update on the distribution of Aedes albopictus (Diptera: Culicidae) in Misiones, Argentina. Rev Inst Med Trop SP 61(e: 46): 1-6.

MANSO HERNÁNDEZ N, CASERTANO SA, GARIBALD JF, BARRIOS CARO LX, HERRERA JR \& CORREA F. 2010. Plan de Manejo del Parque Provincial Puerto Península. Planificación de las Áreas Protegidas del Núcleo Norte de la Provincia de Misiones. Proyecto Araucaria XXI. AECID-APN MERNRyT de Misiones, Inédito, 186 p.

MCCRAY EM, FAY RW \& SCHOOF HF. 1970. The bionomics of Lankesteria culicis and Aedes aegypti. J Invertebr Pathol 16: 42-53.

MILLER BR, MITCHELL CJ \& BALLINGER ME. 1989. Replication, tissue tropisms and transmission of yellow fever virus in Aedes albopictus. Trans R Soc Trop Med Hyg 83: 252-255.

MITCHELL CJ, MONATH TP, SABATTINI MS, DAFFNER JF, CROPP CB, CALISHER CH, DARSIE JR RF \& JAKOB WL. 1987. Arbovirus isolations from mosquitoes collected during and after the 1982-1983 epizootic of western equine encephalitis in Argentina. Am J Trop Med Hyg 36: 107-113.

MORALES ME, OCAMPO CB, CADENA H, COPELAND CS, TERMINI M \& WESSON DM. 2005. Differential identification of Ascogregarina species (Apicomplexa: Lecudinidae) in Aedes aegypti and Aedes albopictus (Diptera: Culicidae) by Polymerase Chain Reaction. J Parasitol 91(6): 1352-1356.
MUNSTERMANN LE \& WESSON DM. 1990. First record of Ascogregarina taiwanensis (Apicomplexa: Lecudinidae) in North American Aedes albopictus. J Am Mosquito Contr 6(2): 235-243.

OYARZABAL M ET AL. 2018. Unidades de Vegetación de La Argentina. Ecología Austral 28(1): 40-63.

PASSOS RA \& TADEI WP. 2008. Parasitism of Ascogregarina taiwanensis and Ascogregarina culicis (Apicomplexa: Lecudinidae) in larvae of Aedes albopictus and Aedes aegypti (Diptera: Culicidae) from Manaus, Amazon Region, Brazil. J Invertebr Pathol 97(3): 230-236.

PEREIRA TN, PROPHIRO JS, LIBERATO DA SILVA G, DE OLIVEIRA JG \& SANTOS DA SILVA O. 2018. Ascogregarina (Apicomplexa: Lecudinidae): An overview of its distribution and pathogenicity on Aedes aegypti and Ae. albopictus development. Biotemas 31(3): 1-13.

PROPHIRO JS, NUNES PEREIRA T, DE OLIVEIRA JG, DANDOLINI GW, NAVARRO DA SILVA MA \& SANTOS DA SILVA O. 2017. Ascogregarina taiwanensis Infection in Aedes aegypti and Aedes albopictus in Santa Catarina, South Brazil. Rev Soc Bras Med Trop 50(2): 235-238.

REYES-VILLANUEVA F, BECNE JJ \& BUTLER JF. 2001. Morphological traits for distinguishing extracellular gamonts of Ascogregarina culicis and Ascogregarina taiwanensis in Aedes aegypti and Aedes albopictus." J Invertebr Pathol 77(3): 227-229.

ROSSI G, PASCUAL NT \& KRSTICEVIC FJ. 1999. First record of Aedes albopictus (Skuse) from Argentina. J Am Mosq Control Assoc 15(3): 422.

SOUZA-NETO JA, POWELL JR \& BONIZZONI M. 2019. Aedes aegypti Vector Competence Studies: A Review. Infect Genet Evol 67: 191-209.

STEIN M. 2018. Aedes albopictus presente en Argentina: algunas consideraciones sobre su bionomía. XI Jornadas Regionales sobre Mosquitos, Ed. AM Visintin, 85 p.

VEGA-RÚA A, ZOUACHE K, GIROD R, FAILLOUX A \& LOURENÇODE-OLIVEIRA R. 2014. High Level of Vector Competence of Aedes aegypti and Aedes albopictus from Ten American Countries as a Crucial Factor in the Spread of Chikungunya Virus. J Virol 88(11): 6294-6306.

VEZZANI D \& WISNIVESKY C. 2006. Prevalence and seasonality of Ascogregarina culicis (Apicomplexa: Lecudinidae) in natural populations of Aedes aegypti (Diptera: Culicidae) from temperate Argentina. J Invertebr Pathol 91(3): 183-187. 


\section{How to cite}

ALONSO AC, STEIN M \& MICIELI MV. 2021. Presence of Ascogregarina culicis and Ascogregarina sp. in natural sympatric populations of Aedes aegypti and Ae. albopictus (Diptera: Culicidae) in Argentina. An Acad Bras Cienc 93: e20200058. DOI 10.1590/0001-3765202120200058.

Manuscript received on January 2, 2020;

accepted for publication on April 13, 2020

\section{ANA C. ALONSO ${ }^{1,3}$}

https://orcid.org/0000-0002-3460-5337

\section{MARINA STEIN ${ }^{1,3}$}

https://orcid.org/0000-0001-7102-9474

\section{MARÍA V. MICIELII ${ }^{2,3}$}

https://orcid.org/0000-0003-0616-2214

${ }^{1}$ Universidad Nacional del Nordeste (UNNE), Instituto de Medicina Regional, Área de Entomología, Avda. Las Heras, 727, 3500 Resistencia, Chaco, Argentina ${ }^{2}$ Centro de Estudios Parasitológicos y de Vectores/ CEPAVE, CONICET-CCT-LA PLATA, Boulevard $120 \mathrm{~s} / \mathrm{n}$ e/61 y 62, 1900 La Plata, Buenos Aires, Argentina ${ }^{3}$ Consejo Nacional de Investigaciones Científicas y Técnicas (CONICET), CCT, Nordeste, Corrientes and La Plata, Buenos Aires, Argentina

Correspondence to: Ana C. Alonso

E-mail:caroalons03081@yahoo.com.ar

\section{Authors contributions}

MS and MVM designed mosquito collection; ACA collected mosquito samples, identified mosquito samples and dissected the larvae; all authors draft the manuscript.

\section{(cc) BY}

